\title{
МЕТОДИКА ПОСТРОЕНИЯ МОДЕЛИ РЕГУЛИРОВАНИЯ ПРОЦЕССОВ КЛАСТЕРИЗАЦИИ И ИННОВАЦИОННОГО РАЗВИТИЯ ЭКОНОМИЧЕСКИХ СИСТЕМ РОССИЙСКИХ РЕГИОНОВ
}

\author{
(C) 2020 Ларионова Нина Ивановна \\ доктор экономических наук, профессор кафедры экономической теории \\ Поволжский государственный технологический университет, Россия, Йошкар-Ола \\ E-mail: LarionovaNI@volgatech.net \\ (c) 2020 Напольских Дмитрий Леонидович \\ кандидат экономических наук, доцент кафедры управления и права \\ Поволжский государственный технологический университет, Россия, Йошкар-Ола \\ E-mail: NapolskihDL@yandex.ru
}

\begin{abstract}
Объектом исследования являются методологические подходы к разработке модели кластеризации и инновационного развития на региональном уровне. Целью работы является разработка методики регулирования процессов кластеризации и инновационного развития российских регионов. Выделены пять этапов в рамках модели регулирования процессов кластеризации и инновационного развития региональных экономических систем. В рамках выделенных этапов формирования модели кластеризации обобщены основные функции органов государственной власти и местного самоуправления в рамках политики кластеризации и инновационного развития российских регионов. Методологической особенностью предлагаемой методики является учёт общей стратегии социально-экономического развития региона, с которой согласуется кластерная политика, а также учёт специфики развития региона с точки зрения пространственного и институционального аспектов.
\end{abstract}

Ключевые слова: кластерная политика, моделирование кластера, инновационное развитие, государственное регулирование, синхронизация развития.

Введение. Существующие в рамках современной российской и зарубежной экономической мысли подходы к инновационному развитию территории региона сходятся во мнении, что наиболее востребованной пространственноорганизационной формой инновационной трансформации экономического пространства является кластер [2,5,8]. Методологический инструментарий кластерной политики даёт возможность взаимосогласования программ территориального развития и корпоративно-отраслевых стратегических приоритетов, что актуально для регионов, экономический профиль и специализация территориально-производственного комплекса которых формируется небольшим числом крупных бюджетообразующих предприятий и научно-образовательных учреждений регионального уровня [3].

Приоритетными для государственной поддержки кластеризации на сегодняшний день

являются те регионы, которые активно формируют кластерные инициативы и одновременно инновационными лидерами [1]. При этом в современных российских условиях кластеризация экономических систем регионов, не вошедших в «первую волну» кластеризации экономики страны, представляется одним из внутренних резервов преодоления экономического спада 2020 года. Институциональная среда инновационных кластеров позволяет урегулировать в долгосрочной перспективе государственные и корпоративно-отраслевые интересы, также следует подчеркнуть роль кластерных механизмов диверсификации рисков создания наукоёмкого и высокотехнологичного производства $[4,6,9]$.

Построение модели регулирования процессов кластеризации и инновационного развития региона представляет собой поэтапное упорядочивание процесса принятия ключевыми субъектами региональной экономиче-

\footnotetext{
* Работа выполнена в рамках гранта Российского фонда фундаментальных исследований 18-010-00647A «Разработка многоуровневой модели синхронизации процессов кластеризации и инновационного развития экономического пространства российских регионов».
} 
ской системы управленческих решений. Сложность научной задачи разработки для каждой конкретной территории комплексной модели регулирования процессов кластеризации и инновационного развития заключается в необходимости определения и согласования как основных параметров (специализация и состав организаций-участников кластера, институты инновационного развития территории и т.д.), так и второстепенных параметров функционирования кластеров [10,11]. Также на процесс построения модели кластеризации и инновационного развития территории оказывает прямое либо косвенное влияние ряд социальноэкономических факторов, что обуславливает использование системного подхода и принципа комплексности. Рассмотренные выше положения определили актуальность, цель и задачи настоящего исследования.

Результаты исследования. В ходе работы были обобщены полученные ранее результаты исследования процессов формирования и развития кластеров на региональном уровне, в частности авторские подходы к идентификации и оценке уровня развития инновационных кластеров. Систематизация данных подходов позволила разработать методику построения модели регулирования процессов кластеризации и инновационного развития экономики российских регионов. Предлагаемая методика последовательно объединяет совокупность организационных и пространственных форм, механизмов и инструментов кластерного развития.

Методика построения модели регулирования процессов кластеризации и инновационного развития экономических систем российских регионов включает в себя следующие этапы.

Первый этап: методическая и организационная подготовка отбора региональных кластерных инициатив с целью формирования кластеров, соответствующих целям синхронизации процессов инновационного и кластерного развития территории. В рамках данного этапа последовательно реализуются следующие действия:

1.1. оценка экономического развития региона и отраслевой структуры его экономики, анализ развития региональной инновационной системы (РИС);

1.2. выделение в рамках экономического пространства региона территорий, обладающих предпосылками к кластерообразованию;
1.3. уточнение методов и инструментов идентификации кластерных образований;

1.4. идентификация функционирующих кластеров и протокластеров на территории региона.

Второй этап: формирование институциональной структуры управления процессами кластеризации и инновационного развития отобранных инициатив. В рамках данного этапа последовательно реализуются следующие действия:

2.1. разработка/уточнение стратегии кластерного развития на основе синхронизации со стратегиями и программами инновационного и социально-экономического развития;

2.2. анализ цепочек формирования добавленной стоимости кластера с целью выявления смежных этапов и технологических переделов, идентификация ядра кластера, инновационных контуров, а также многоотраслевых и многоуровневых производственных циклов;

2.3. формирование организационной структуры кластера, на основе интеграции устоявшихся форм экономической деятельности в рамках выявленных смежных территориальнопроизводственных комплексов;

2.4. формализация институциональной структуры управления процессами кластеризации и инновационного развития.

Третий этап: регулирование участия предприятий и организаций кластера в федеральных и региональных программах поддержки инновационного и территориального развития. В рамках данного этапа последовательно реализуются следующие действия:

3.1. имплантация в институциональную среду кластера успешно-функционирующих организационно-управленческих механизмов на основе диффузии инновационных технологий, применяемых на федеральном и региональном уровнях;

3.2. экономическое обоснование участия кластеров в федеральных программах инновационного и промышленного развития, формирование системы информационно-методического обеспечения;

3.3. разработка механизмов поддержки процессов кластерного развития: целевые инвестиции и субсидирование, налоговые и иные льготы;

3.4. Создание благоприятного инвестиционного климата кластерного развития за счёт совершенствования институциональной среды 
территории;

Четвёртый этап: формирования региональных институтов инновационного и промышленного развития, содействующих привлечению частных инвестиций в совместные проекты участников кластера, а также обеспечивающих комплексное развитие экономики региона. В рамках данного этапа последовательно реализуются следующие действия:

4.1. разработка инструментов поддержки выхода высокотехнологичной продукции предприятий кластера на международный рынок, а также реализация программ импортозамещения;

4.2. формирование механизмов научнотехнической кооперации с зарубежными партнерами организаций-участников кластера, а также привлечения реальных инвестиций из-за рубежа;

4.3. адаптация к целям развития кластера механизмов государственно-частного партнёрства.

Пятый этап: разработка механизма регулирования процессов кластеризации и инновационного развития экономической системы региона. В рамках данного этапа реализуются следующие направления:

5.1. формирование системы пространственного развития региона на основе распределения экстерналий кластерного развития и привлекаемых под кластерные проекты дополнительных ресурсов;

5.2. координация взаимодействия организаций-участников кластеров рамках единой региональной модели развития;

5.3. построение прогнозных моделей результативности и эффективности кластерной политики на основе разработанной системы количественных и качественных показателей оценки процессов;

5.4. корректировка направлений стратегического развития кластера в соответствии с результатами мониторинга результативности и эффективности кластерной политики;

5.5. синхронизация и уточнение стратегии и проектов кластерного развития с программами инновационного развития региона.
Выводы. Таким образом, задачу построения модели регулирования процессов кластеризации и инновационного развития экономических систем российских регионов необходимо решать комплексно, в рамках одной методики, позволяющей согласование классического инструментария кластерной политики с региональными программами и проектами инновационного развития. Применение предлагаемой в работе методики ориентировано на решение следующих практических задач: повышение устойчивости развития экономических систем субъектов РФ, создание методологической основные дальнейшего формирования межрегиональных и межотраслевых кластеров. Предлагаемая методика регулирования процессов инновационного развития основана на кластерных механизмах конкуренции и кооперации, сочетание которых позволяет в условиях современной экономики добиться высокой инновационной активности и интеграции ресурсов региона в рамках приоритетных видов экономической деятельности.

Возможность достижения указанных экономических эффектов от реализации предлагаемой методики обусловлена следующими выводами. Достижение синергетических эффектов от взаимосогласования в рамках одной модели кластера программ территориального развития и корпоративно-отраслевых стратегических приоритетов создаёт положительные экстерналии кластерного развития и формирует институциональные условия для диффузии инноваций, в том числе в масштабах макрорегиона. Перенесение фокуса формирования кластерных инициатив с федерального на региональный уровень управления повышает конкурентоспособность региона в условиях возрастающей регионализации мировой экономики.

Предлагаемая методика построения модели кластеризации даёт возможность уточнения и дальнейшего углубления отраслевой специализации региона преимущественной в сфере наукоёмкого и высокотехнологичного производства. Также при методически грамотной модели кластеризации возрастают институциональные возможности региональных органов исполнительной власти в области обоснования привлечения дополнительных федеральных ресурсов в рамках программ инновационного и промышленного развития. 


\section{Библиографический список}

1. Концепция долгосрочного социально-экономического развития Российской Федерации до 2020 года, Утверждена Распоряжением Правительства РФ № 1662-р от 17 ноября 2008 года [Электронный ресурс].Режим доступа: http://static.government.ru/media/files/aaooFKSheDLiM99HEcyrygytfmGzrnAX.pdf (дата обращения: 3.12.2020).

2. Гусейнов, А.Г. Проблемы формирования региональных кластерных систем /А.Г. Гусейнов, А. З. Гаджиев // Фундаментальные исследования.-2016.- № 3-2.- С. 360-367

3. Домбровский, М.А. Методологические проблемы экономической кластеризации [Электронный ресурс] / М.А.Домбровский // Проблемы современной экономики. - 2011. - № 2.- Режим доступа: https:// cyberleninka.ru/article/n/metodologicheskie-problemy-ekonomicheskoy-klasterizatsii （дата обращения: 3.07.2020).

4. Ларионова, Н.И. Концептуальные основы структурной диверсификации экономики / Н.И.Ларионова, Н.Л.Загайнова // Вестник Поволжского государственного технологического университета. Серия: Экономика и управление.-2009.- № 2.-С. 17-29.

5. Марков, Л.С. Теоретико-методологические основы кластерного подхода [Текст] / Л.С. Марков.- Новосибирск: ИЭОПП СО РАН, 2015.- 300 с.

6. Найдёнов, Н.Д. Экономико-математические модели кластера [Текст] / Н.Д.Найдёнов, В.И.Спирягин, Е.Н. Новокшонова // Современные исследования социальных проблем. - 2015. - № 9 (53). - C. 415-432.

7. Российская кластерная обсерватория. [Электронный ресурс].- Режим доступа: https://cluster.hse.ru/ (дата обращения: 3.12.2020).

8. Enright, M. J. Survey on the Characterization of Regional Clusters: Initial Results. Working Paper // Institute of Economic Policy and Business Strategy: Competitiveness Program University of Hong Kong. 2000. 21 p.

9. Ketels, Ch., G.Lindqvist, Ö. Sölvell. Strengthening Clusters and Competitiveness in Europe. The Role of Cluster Organizations. URL: http://gosbook.ru/node/84334. дата обращения: 3.12.2020).

10. Lundvall B. National Systems of Innovation: Towards a Theory of Innovation and Interactive Learning.- L.: Pinter Publishers. 1992.- 317 p.

11. Morisson, A. \& Doussineau, M. Regional innovation governance and place-based policies: design, implementation and implications. Regional Studies, Regional Science,6(1), 2019, 101-116. URL: https://rsa.tandfonline.com/doi/ full/10.1080/21681376.2019.1578257. 